\title{
$\stackrel{\alpha}{\underline{\alpha}}$ NTERNATIONAL REVIEW Of SOCIAL RESEARCH
}

\section{Human Capital for a Planned Economy Relations of Correspondence and Unintended Consequences in the Higher Education of Communist Romania}

\author{
Lazăr VLĂSCEANU• \\ Marian-Gabriel HÂNCEAN \\ Department of Sociology, University of Bucharest
}

\begin{abstract}
Our main purpose was to look into the correspondence relation between the macrolevel normative planning within higher education (implemented by the Romanian communist state) and the de facto micro-level occupational mobility of higher education graduates. We unraveled a consistent lack of correspondence between higher education graduates' flows and economic production, split on different areas (i.e. industry, agriculture, services). In this light, the production of services significantly increased during communism, given an insignificant oscillation in the number of specialists in services, and in spite of the state's priority to support industrial production by sustaining large numbers of technical higher education graduates. Identifying time series data on education, population and economy, we explored trends from cross national (i.e. Romania in the context of the Eastern Communist Block) and cross topic (i.e. education, demography and economy) perspectives. We used regression equations to estimate linear trends, the Dickey-Fuller test for stationary checking, and the original stationary variable differencing for oscillation comparative purposes. Our main finding was that the inflation of technical higher education graduates, triggered by the Romanian communist state to support the industry, backfired an informal individual occupational mobility towards urban areas that offered jobs in the service sector.
\end{abstract}

Keywords: higher education in communism, Romania, undergraduate flows, planned economy.

The planning of skills and of qualified persons' flows, and cultural reproduction were two of the key aims of rationalizing a society based on the communist social order. While the former was future oriented, the latter aimed for the preservation of the preestablished communist principles and

•e-mail: lazarvlasceanu@gmail.com. Lazăr Vlăsceanu, Ph.D., is a professor of sociological research methodology at Bucharest University, Department of Sociology. He has been involved in various projects related to higher education policy design and implementation, both in Romania and elsewhere. He published research papers and volumes on social research methodology, sociology of education and culture, and higher education reform and policy making. More recently, his research interests have focused on social and cultural issues of higher education in the age of reflexive modernity (Cf. Universities and Reflexive Modernity. Institutional Ambiguities and Unintended Consequences, CEU Press, 2010). Marian-Gabriel Hâncean, Ph.D., is associate professor/lecturer of Organizational Sociology and Networks at University of Bucharest, Department of Sociology. He is also an affiliated member of International Network for Social Network Analysis and of Romanian Sociological Society. His main research streams are focused on understanding both organizational performance from a social network perspective, and the behavior of public organizations within higher education field. 
values. Communist rationalization was the aim of everyday concerns, and offered the necessary bridge between the reproduction of the past and the planned projections of the future. As it were, no future achievements could be envisaged without a closer and ever more enlarged reproduction of that past which was shaped by the unquestionable communist principles and values. Such a paradoxical orientation of the communist social order (i.e. that of realizing the future with the values of the past) was to be achieved primarily by the education system.

As a matter of fact, the education of the masses held a key position during the communist regime. The reason may seem obvious: it is in the very nature of education to use the products of the past in order to generate future individual embodiments. In the case at hand, once the past is established under the form of communist principles and values, their reproduction through education should be kept under tight control. The planning of education flows meant not only the provision of human capital, but also the achievement of the system's ideological and cultural reproduction.

When accepting such a view on the communist rationalization of its social order, a question may be raised: did the communist social order manage to identify and keep in a steady state the correspondences between the planned education flows and the reproduction of individual embodiments of cultural and ideological principles and values? Were there any unexpected consequences that turned against the planned criteria of efficiency and rationalization?

In order to answer such questions, a closer look at the relationships between planning in education and its reproductive effects in the wider social system is necessary. In what follows, we will firstly look at such relationships in order to launch a number of hypotheses, and then test them against data available on the Romanian communist system of higher education.

\section{Planning under the communist social order}

Under the former Romanian political regime, education was considered, as in any other communist country, a social subsystem meant to produce the human capital required by economic production. However, not any type of human capital was expected to be generated, but only that which was closely associated with a cultural capital whose constitutive axis was represented by the communist ideological principles and values.

In the education field, planning was the key mechanism and practice for achieving both human and cultural capital. That is, educational flows were periodically planned - usually every five years - so as to generate, in each and every area of goods and services, the production of the work force that would fill in new openings, and be equipped with the necessary cultural capital particularized by the individual ethos. Educational flows were considered as being objectively demanded by the economic, political and ideological system in order to ensure its reproduction. The flows of human and cultural capital were closely estimated and controlled through the mechanism and practice 
of planning. Consequently, the main rationale of planning was to ensure the enlarged reproduction of the functional communist order in the national system.

Planning was applied to the social system as a whole, and to each of its components, thus being as pervasive as it was normative. The key assumption of planning was that it brought about and maintained rationality in a social system entirely oriented towards a promising bright future. Normative criteria of efficiency were preestablished, while projected objectives were expected to be necessarily achieved. Additionally, the rationality of planning was set to be the means to achieve the effective reproduction of the existing social, political and cultural order.

Drawing on the internal logic of the communist regime, two important organizational bodies held the key positions in the power system: the State Planning Committee - responsible for economic reproduction and the Central Committee of the Romanian Communist Party - responsible for cultural reproduction. The two organizational bodies were perceived as the two sides of the same coin. Though their responsibilities were different to a certain extent, their actions were guided by the same rules and logic of social order reproduction.

The idea of planning under communist rule can be better understood if we point out some of its key features. Firstly, planning basically relied on a systemic approach, society being defined as an integrated block, where all the parts had to fit in the overall national puzzle. Secondly, planning was envisaged as the best mechanism for ensuring the application of rationality criteria in a society which otherwise would divert into chaotic development. Thirdly, planning was meant to predict the future by 5-year cycle estimated results. And fourthly, planning operated with efficiency principles of optimization that were based on the use of ex-post assessment (i.e. the implemented system was compared with the planning model in order to draw subsequent decisions of adjustment). In other words, planning was a mixture of systemic thinking, rationality, prediction and constant adjustment.

One of the main problems that communist planning had to solve derived from its ex-post assessment of public policies. Namely, the observed system dynamics had to comply with planned dynamics in order to preserve the rationality of the system. Such correspondence between observed and expected outcomes was the main mechanism which link economic planning to cultural reproduction. In this respect, two issues deserve a closer scrutiny. Firstly, it is an evaluation of this correspondence and, secondly, there is the problem of measuring the extent to which that correspondence properly met the ideological needs of the system. That is, between planning, as a means of system rationalization, and reproduction, as a means of system implementation and preservation, there is the process of emerging correspondences between system inputs and outputs. Failed correspondences due to unintended consequences would negatively influence the system reproduction and, thus, would endanger its very survival.

In order to test such a statement, referring to the correspondence 
between observed and expected outcomes in higher education, and their unexpected consequences, let us take a look at undergraduate flows in higher education.

\section{Mechanisms of higher education planning}

As mentioned above, higher education planning in a communist society aimed at the reproduction of its social order. There were two levels of planning higher education undergraduate flows: an individual level and a systemic one.

At the individual level of higher education planning, every student had to plan his/her prospects of academic development so as to make sure that his/her academic achievements would guarantee a job best corresponding to their expectations in terms of prospects of personal development after graduation. Work places were offered by state bodies to all graduates based on their academic achievements. The graduates' academic itinerary dictated the position they would hold on a scale of academic achievements measured by individual average marks. After graduation, all the graduates' average marks were then scaled down at national level for every field of study. A graduate's prospects of being granted a good job depended on his/her positioning on the scale.

Figure 1 illustrates two pyramids operating in the process of establishing correspondences between academic achievements and work appointment after graduation: one refers to the scale of graduates' average marks, while the other, to all work appointments offered by the government to the graduates of a given study program.
The former features a hierarchy which is skewed at the top: a smaller number of graduates with higher marks is followed by an increasing number of graduates with smaller marks. The latter features a hierarchy of individual work appointments. This was skewed at the basis: a smaller number of highly desirable work appointments were counterbalanced by a much larger number of less desirable ones. When correlating the scale of work appointments with the scale of academic achievements, the asymmetry of choice making is obvious: the higher a graduate's mark, the larger the range of potential jobs s/he could choose from. The two pyramids also comprise two additional variables which impacted the meritocratic correspondence between academic achievements and work appointments.

One such variable referred to the political activism and loyalty demonstrated by a graduate during her period of study. This politicized variable contributed a considerable bonus, and it could often attenuate or, more rarely, increase the effects of academic achievement. The other variable was more informal, and referred to the informal connections some families could have and use for their offspring in order to eliminate the effects of the meritocratic process. The two intervening variables, generated by the needs to achieve cultural reproduction, operated in such a way that they distorted the expected correspondences operating in individual meritocratic educational planning. Thus, cultural reproduction purposes proved to be more powerful than the individual meritocratic planning of educational achievement. 




a

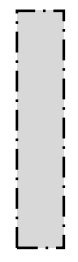

C

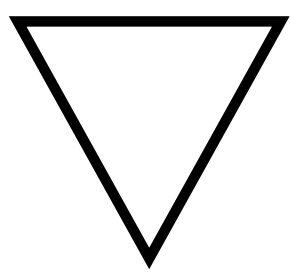

b

Figure 1. Pyramids operating in the process of establishing correspondences between academic achievements and work appointment after graduation, within Romanian higher education during the communist rule.

Note: Figure 1a shows the distribution of graduates based on their marks (the pyramid of academic achievement). Figure 1b shows the distribution of individual work appointments (the pyramid of work opportunities) directly related to the pyramid of academic achievements. Figure 1c shows residual variables (politically oriented or dictated by the existence of family connections) that bias the correspondence between the two pyramids.

The mechanism operating in individual planning was meant to generate a meritocratic academic ranking of higher education graduates. The higher the position one held on the scale, the wider the range of choices and the better the chances of choosing a work place which ensured better prospects for future personal development. However, this mechanism worked only in theory. Factual information contradicted it constantly. Firstly, the higher one's academic performance, the more limited the range of choices available, because: (a) the best or the most desirable jobs were reserved by the Party elite in order to be later distributed according to the Party interests; (b) very few, if any, good jobs were open to new graduates, but the practice was to send the best graduates to the least prestigious areas of work, in the hope that they would help increase the productivity level. Consequently, meritocracy was disregarded, and the informality of work appointments became the rule. Intervening actions disturbed the functioning of the meritocracy principle and paved the way for informality and corruption practices. The correspondences between individual planning and reproduction failed systematically in an increasingly corrupted system.

At the systemic level, the planning of undergraduate flows by study programs was expected to meet the economic demands of labor market division. It follows that, from this perspective, the observed outcomes of the higher education system had to match up the expected outcomes on the labor market. Consequently, a perfect balance of inputs and outputs on the labor market was expected, as was logical.

However, as shown below, neither individual level planning, nor systemic level planning was successful. Actually, higher education planning under communist rule proved to be a clear case of failure, as the planned model did not match the observed one (i.e. the labor market faced a rather imperfect balance). Moreover, processes of social informality and downright 
corruption impinged upon the relations of correspondence, and thus on the expected cultural reproduction of the communist system.

\section{Data and results}

Based on the collected time series data from multiple sources available (Axenciuc 2012; Barro and Lee, 2013; EUROSTAT, 2014; Maddison, 2012; National Statistics Committee, 1996), in this section we present descriptive statistics on education (i.e. graduate flows, education level attainment for population aged $25+$ ), population (i.e. urban and rural) and economy (i.e. gross domestic product, the production of industrial and agricultural goods and of services). We explored the trends within the time series data from a cross national (i.e. Romania in the context of the Eastern Communist Block) and cross topic (i.e. education, demography and economy) perspective. Our analysis was run on time series data collected for the period 1950 - 1990 (i.e. our historical time reference of interest, the communist period). Our analysis of the raw data focused on unraveling or identifying regularities derived from the Romanian communist state's planning of human capital, searching for intended and unintended consequences. While looking at and going through the time series data, we have used: regression equations in order to estimate linear trends, the Dickey-Fuller test for stationary checking, and the original stationary variable differencing for oscillation comparative purposes.

Under the communist regime, Romanian education was considered a national state priority. An educated society meant the education of the masses. The sequence of primary, lower secondary and upper secondary schooling was an educational priority. Cultural reproduction was to be achieved through education of the masses, which would thus acquire both basic knowledge and communist values.

\section{Schooling massification}

As shown in Figure 2, the average years of schooling significantly increased over a period of 40 years (i.e. from 1950 to 1990). For illustrative purposes, based on the raw data collected by Barro and Lee (2013) and having as a reference the population aged 25 years and more, we plotted not only the average years of total schooling, but also the average years on different levels of schooling. For example, the average years of schooling increased from three point nine years, in 1950, to nine years in 1990, which marks an average growth of approximately five years. Positive slopes are also visible when looking into education attainment in case of primary, secondary and tertiary schooling.

As shown in Figure 3, under communist rule, the percentage of the population (aged 25 years and more) lacking any form of educational training, i.e. without any schooling, mainly decreased from 17.2 per cent in 1950 to only five point four per cent in 1990. Moreover, in terms of the highest education level attained, Figure 3 reveals that, in 1990, more than 30 per cent of the population (aged 25 




Figure 2. Average years of schooling trends between 1950 and 1990 for the Romanian population aged $25+$

Source of the raw data: Barro and Lee, 2013.

years and more) managed to complete at least the secondary education level, compared to only one per cent in 1950 .

As for tertiary education trends, Figures 2 and 3 show that even if positive slopes are highlighted, their increase is not as significant as in the case of other education levels. The average years of tertiary education grew from 0.07 years (in 1950) to (only) 0.23 years (in 1990), while the percentage of population (aged 25 years and more) that completed the tertiary education level increased from one point three per cent (1950) to four point five per cent in 1990. These raw data lead to the conclusion that, during the 40 years of communism, increased access to education (defined as average years of schooling or percentage of population that completed a certain education level) was substantial, with significantly different slopes across education levels, the least increase being noted in case of tertiary education level. Given these time series, it is worth noting that cultural reproduction focused on the basic education of the masses and not on the intellectual capital acquired in higher education.

The need for an educated society and for human capital is not a specific characteristic of the Romanian communist architecture. Similar trends in educational planning policies can also be identified in other communist countries stacked in the Eastern Communist Block (such as Bulgaria, Hungary, Poland, Russia, Serbia, Ukraine).

As shown in Figure 4, as compared to other six European communist 


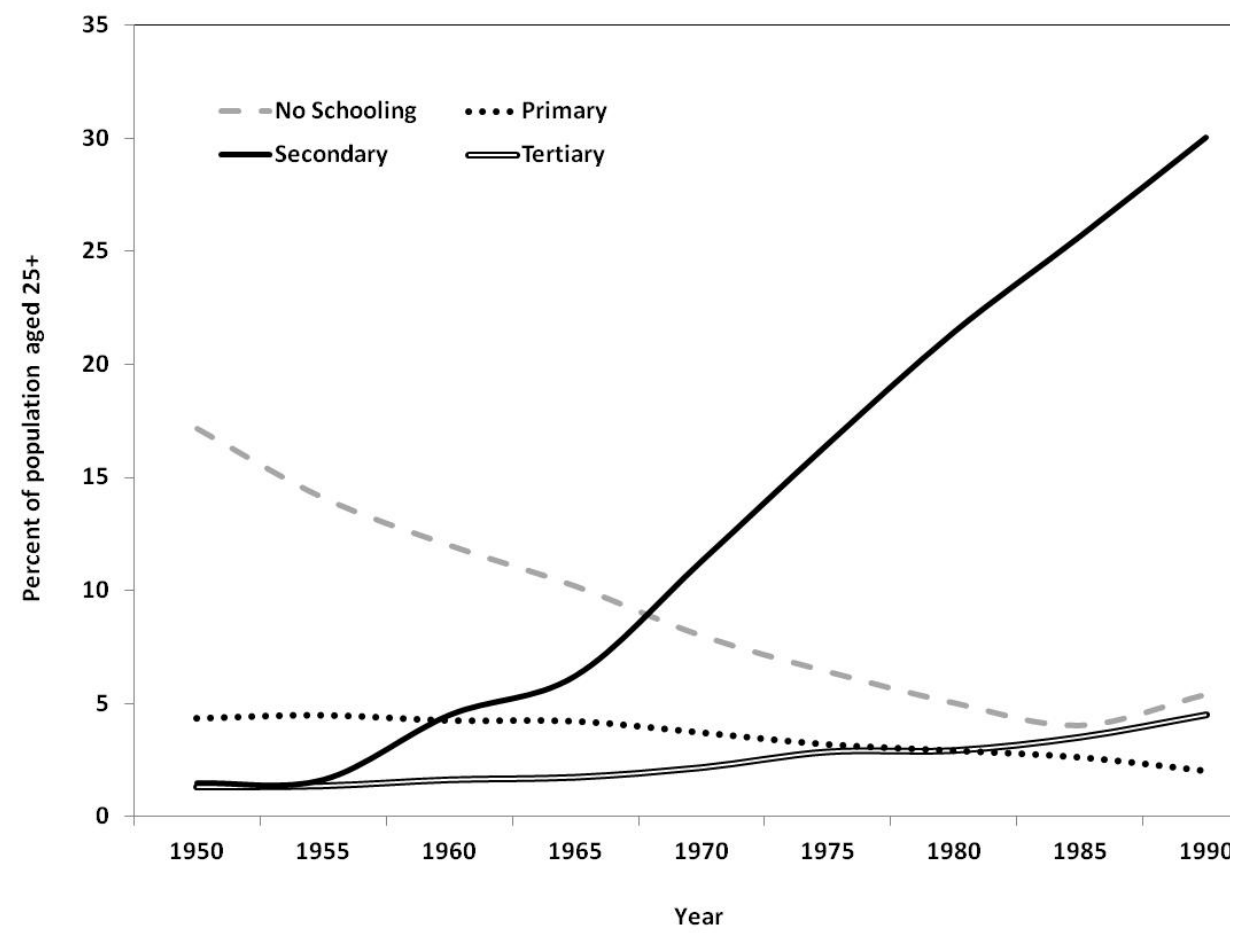

Figure 3. Education level attainment trends by percentage of Romanian population aged $25+$ between 1950 and 1990

Source of the raw data: Barro and Lee, 2013

countries, Romania underwent a slow growth rate in the percentage of population (aged 25 years and more) that completed the tertiary education level. Actually, there are two different patterns of growth of the tertiary education level. There is a number of steeper rises or slopes (as in the case of Russia, Ukraine, Bulgaria and Hungary), but there are also moderate rises (in Serbia, Poland and Romania). For example, in Russia, the percentage of the population that completed a tertiary education level raised from one point forty-eight per cent in 1950 to 14.27 per cent in 1990 , while in Ukraine it increased from one point seventy-five per cent to 13.84 per cent. In Romania, the percentage increased from one point thirty-two per cent (1950) to only four point fifty-two per cent (1990), while in Poland, it increased from one point fifty-five per cent to four point sixty-two per cent. These two different patterns of growth become evident when fitting regression lines to the time series. Table 1 reports the corresponding slope values derived from the linear regression equations computed for each of the seven countries' time series (the slope values are illustrative for the different growth rates). 


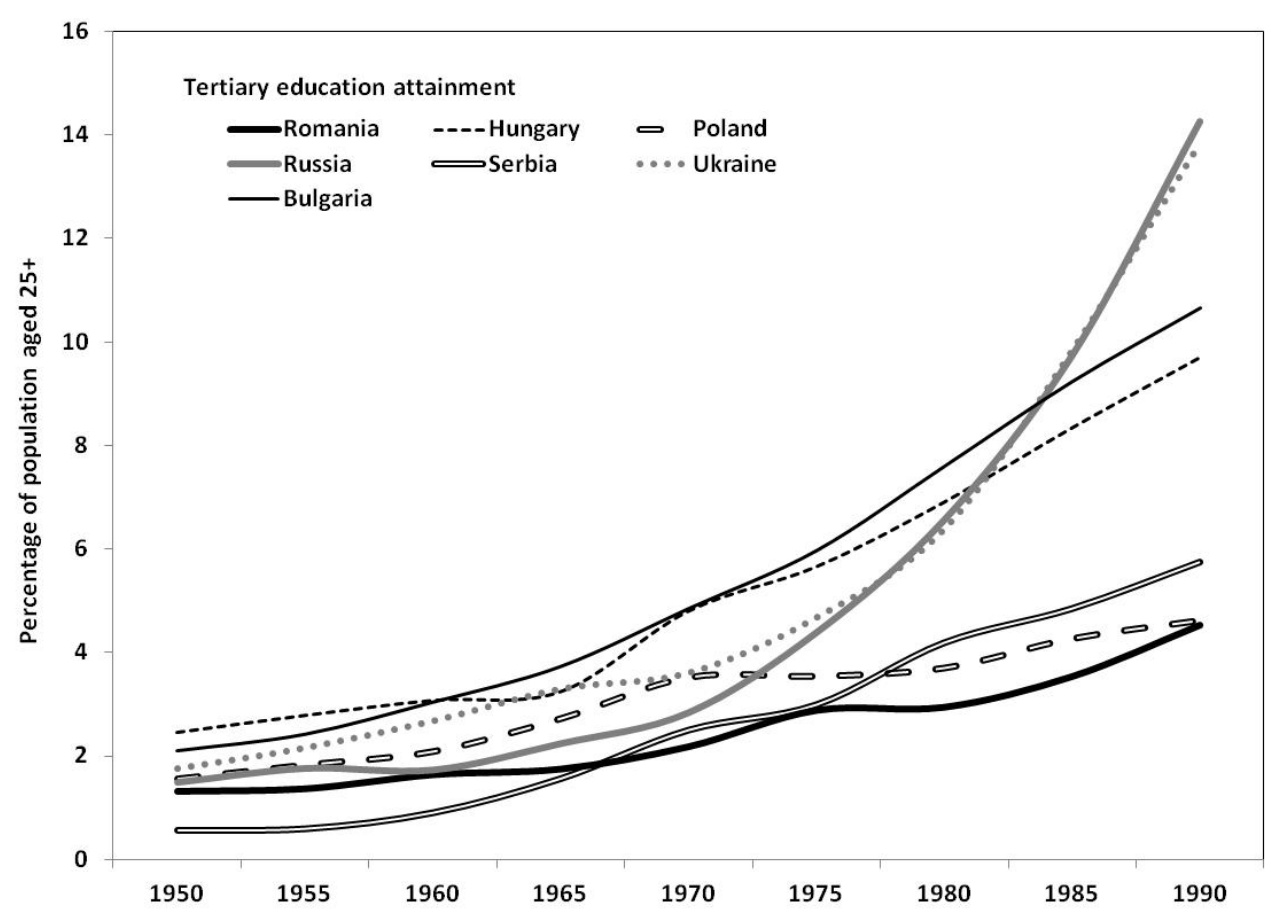

Figure 4. Tertiary education level attainment trends by percentage of population aged 25+ in six Eastern European countries and Russia, during 1950 - 1990

Source of the raw data: Barro and Lee, 2013.

Table 1: Regression equations describing tertiary education level attainment trends (expressed as percentage of population aged $25+$ ) between 1950 and 1990. Results are split on seven countries

\begin{tabular}{cccccccc} 
& Romania & Poland & Serbia & Hungary & Bulgaria & Ukraine & Russia \\
\cline { 2 - 7 } intercept & 0.541 & 1.117 & -0.808 & 0.565 & -0.003 & -1.330 & -2.251 \\
slope & 0.384 & 0.395 & 0.693 & 0.931 & 1.101 & 1.337 & 1.449 \\
\hline
\end{tabular}

The different patterns or rates in the massification of education in the Eastern Communist Block can be also seen in Figure 5, where trends of average years of tertiary education are plotted. However, it must be stressed that, in Figures 4 and 5, the beginning of the eighties proved to be pivotal for the process of education massification. As specified above, in some cases the growth rate was steeper, while in other cases (among which Romania) the trend kept its course on a constant increase (for illustrative purposes, Table 2 shows the slope values corresponding to the regression equations fit to the time series). 


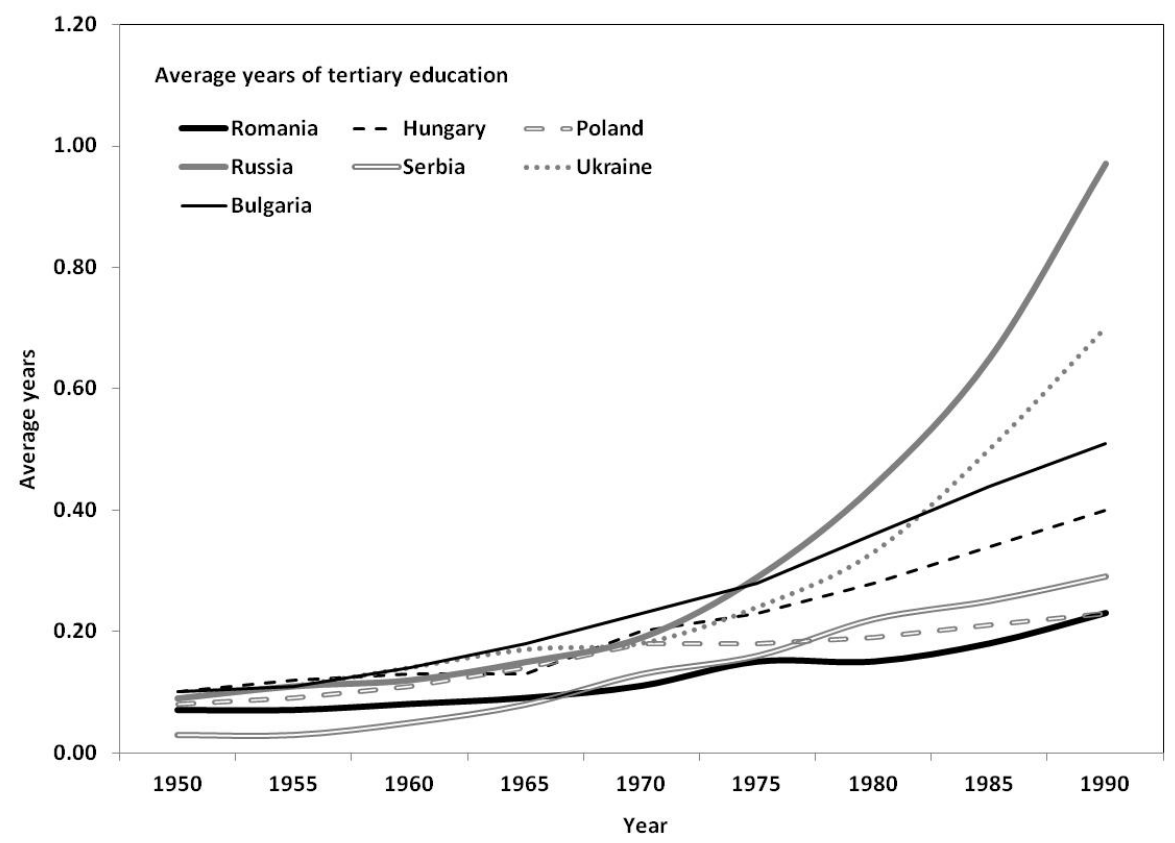

Figure 5. Average years of tertiary education trends between 1950 and 1990 for the population aged 25+ of six Eastern European countries and Russia

Source of the raw data: Barro and Lee, 2013.

Table 2: Regression equations describing average tertiary education level attainment trends between 1950 and 1990 for the population aged $25+$.

Results are split on seven countries

\begin{tabular}{cccccccc} 
& Poland & Romania & Serbia & Hungary & Bulgaria & Ukraine & Russia \\
\cline { 2 - 7 } intercept & 0.06 & 0.028 & -0.039 & 0.026 & -0.003 & -0.065 & -0.159 \\
Slope & 0.019 & 0.020 & 0.035 & 0.038 & 0.053 & 0.068 & 0.099 \\
\hline
\end{tabular}

A general picture of the educational trends in the Eastern Communist Block between 1950 and 1990 is presented in Figure 6. Aggregating the raw data for the seven European communist countries, the conclusion is that the average years of schooling increased both for any level of education attainment (i.e. primary, secondary, tertiary), and for total schooling (for illustration purposes, we checked the non-stationary hypothesis, using the Dickey-Fuller test; the results are reported in Table 3). The comparative framework indicates that Romania had a convergent trajectory with other communist Eastern European countries, even if differences in terms of education massification growth rates can be identified (the slope values are reported in Table 4). 


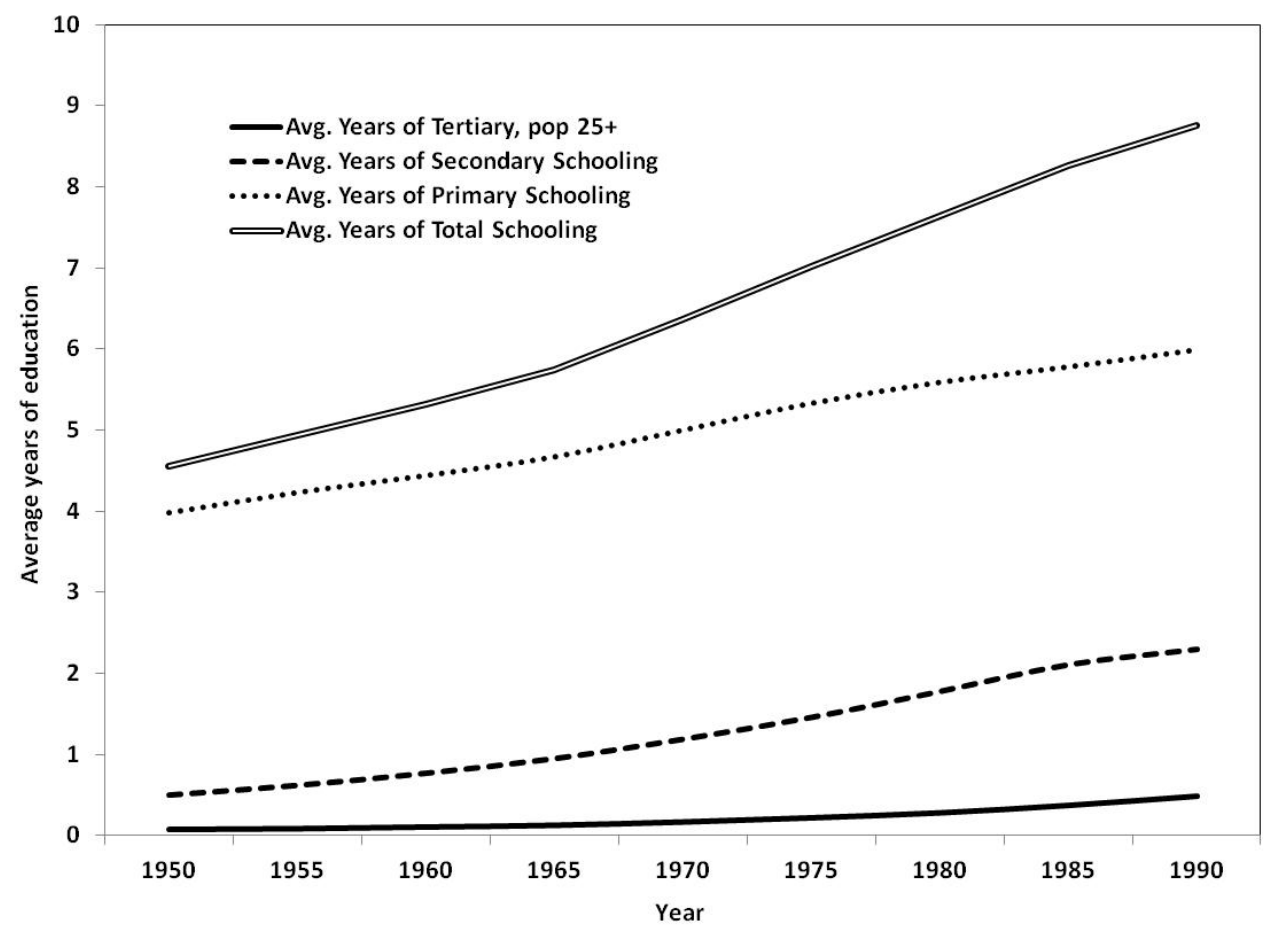

Figure 8. Average years of education trends split on levels of attained education between 1950 and 1990 for the population aged 25+ of six Eastern European countries and Russia Source of the raw data: Barro and Lee, 2013.

Table 3. Testing time series non-stationary (i.e. average years of education trends split on levels of attained education between 1950 and 1990 for the population aged 25+ of seven European countries - Romania, Bulgaria, Hungary, Poland, Russia, Ukraine, Serbia), using the Dickey-Fuller test. Alternative hypothesis: stationary

Variable

Average years of tertiary schooling attained

Average years of secondary schooling attained

Average years of primary schooling attained

Average years of total schooling attained
Dickey-Fuller test p-value

$\begin{array}{lc}-2.157 & .5125 \\ -2.594 & .3462 \\ -0.029 & .99 \\ -1.445 & .784\end{array}$

Table 4. Regression equations describing average tertiary education level attainment trends between 1950 and 1990 for the population aged 25+

Avg. years of tertiary, pop 25+
Avg. years of Secondary Schooling
Avg. years of Primary Schooling

\begin{tabular}{ccccc}
\hline intercept & -0.025 & 0.114 & 3.697 & 3.79 \\
Slope & 0.048 & 0.237 & 0.261 & 0.545 \\
\hline
\end{tabular}

Avg. years of Total Schooling 


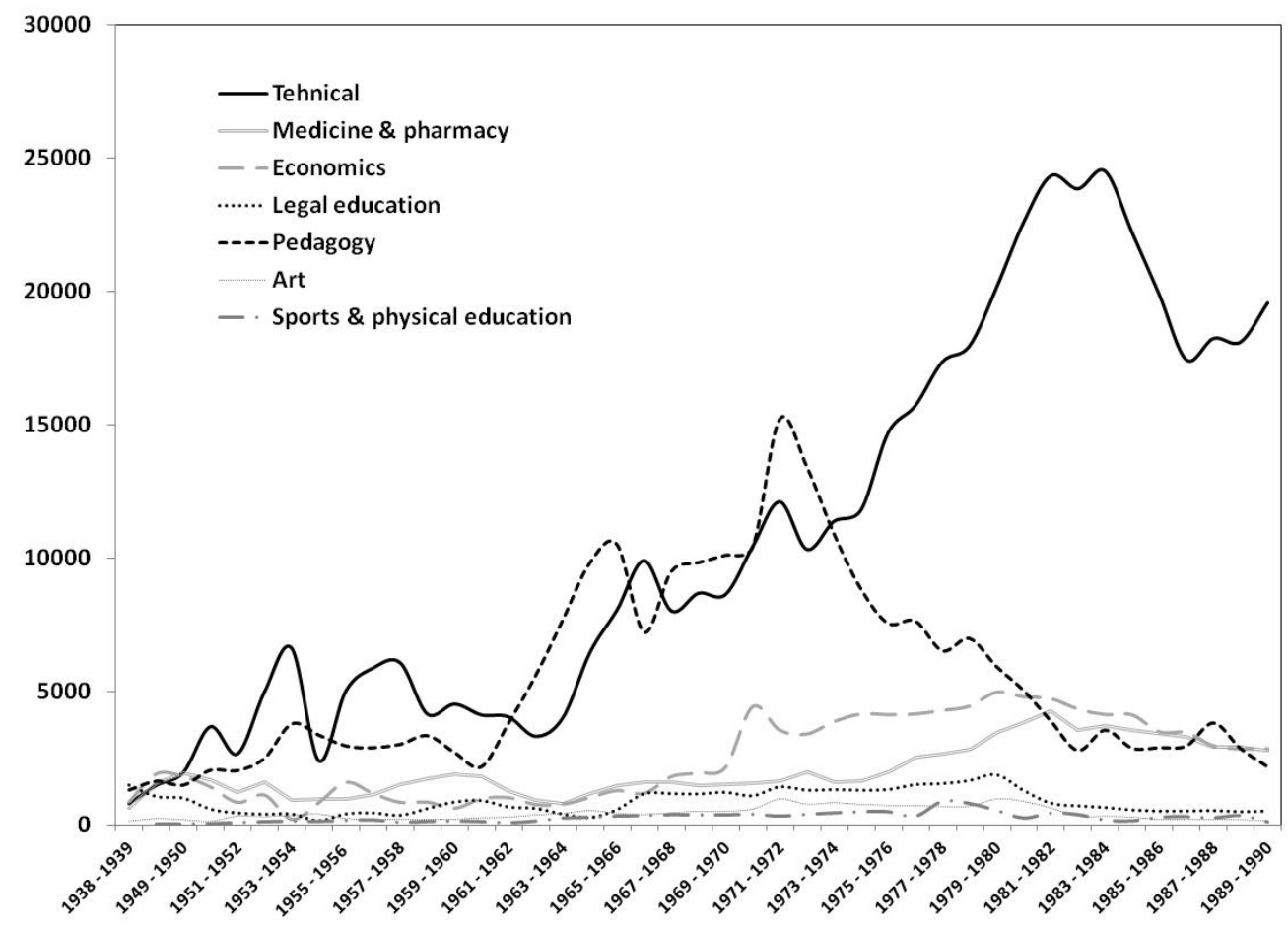

Figure 7. Graduates' flows during the communist rule in Romania split on education specialization

Source of the raw data: National Statistics Committee, 1996.

In respect of the graduates' flows in the higher education system, Figure 7 shows that, during the communist rule, Romanian state authorities placed great emphasis on technical education and, consequently, on pedagogy (i.e. teacher training). For instance, the number of higher education graduates with a technical degree increased from 8,374 in 1950 to 28,113 in 1990. Compared to the flow of graduates in the technical fields of study, the flow of graduates studying pedagogy maintained a rising trend only until 1974. After this time reference, the trend continuously decreased until 1990. The number of graduates from other academic fields of study (i.e. medicine and pharmacy, economics, arts, legal education, sports and physical education) registered variations that never reached 5,000 graduates per year.

The communist political elites of Romania were less willing to invest in and significantly support higher education. Individual intellectual capital and societal cultural reproduction needs were deemed contradictory, with the former negatively impacting the latter. Correspondences between educational planning and individual intellectual development were established only for lower schooling levels and, thus, for wider cultural reproduction, preventing the development of intellectual capital that could have challenged the mere reproduction of the system's values and ideology. 
Labor market and industrialization

Between 1950 and 1990, Romania underwent a rapid process of urbanization and industrialization. As shown in Figure 8, the urban population increased constantly, from 4,035,000 in 1950 to more than $12,312,000$ in 1989. In addition, employment in industrial sectors followed the urbanization raising curve, and in the late seventies, it exceeded employment rates in agriculture. Moreover, the increase of population living in urban areas and employed in industry was positively associated with a constant increase of the gross domestic product per capita.



Figure 8. Trends in population (urban and rural population) and GDPpc between 1950 and 1989, in Romania

Source of the raw data: Axenciuc, 2012; Bolt and van Zanden, 2013.

As shown in Figure 9, the constant increase in industrial employment, that was supported by the state economic planning during all communist periods, was positively associated with the increased production of goods in industry. Additionally, the production of goods in agriculture also increased (but at a much slower rate than the production of goods in industry and services), in spite of a substantial decrease of the number of people employed in agriculture.
Industrialization is also visible from the analysis of the graduates' flows. For illustrative purposes, in Figure 10 we indicate the trend of higher education graduates, expressed as a percentage of the total population of higher education graduates. As shown above, at the end of the seventies, more than half of the higher education graduates had a university degree in a technical field. 


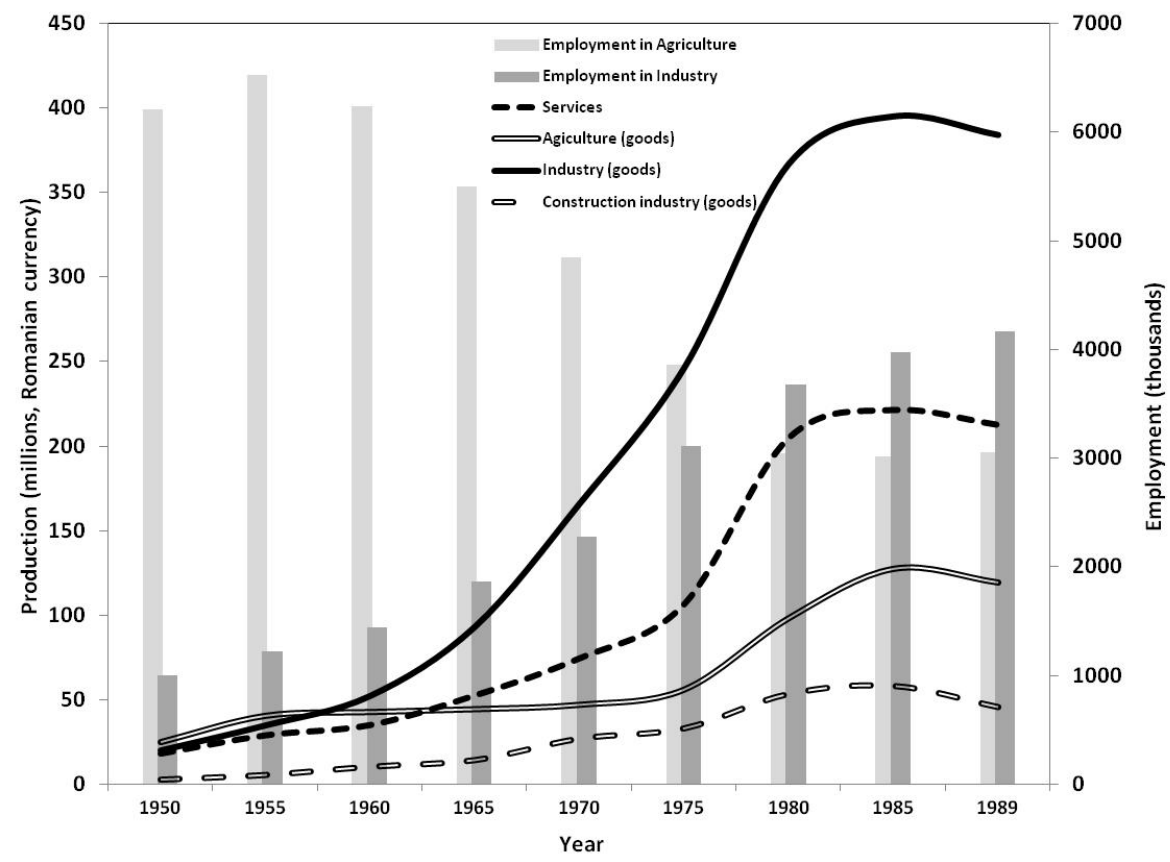

Figure 9. Employment (split on industry and agriculture - expressed in thousands of workers) and the production of services and goods (split on industry, construction industry and agriculture - expressed in millions of Lei, Romanian currency), for Romania, between 1950 and 1989.

(Source of the raw data: Axenciuc, 2012)

In the context of the Romanian communist regime's strategy to produce high numbers of graduates in technical fields (designed to support the industrialization and production of industrial goods), a particular phenomenon deserves special attention. While delivering higher education graduates for the economic field of services was not a state priority, the production of services (expressed in millions of Lei - Romanian currency) constantly increased (Figures 9 and 11). In other words, the number of graduates in the fields of economics and legal education fluctuated mildly between 1950 and 1990, without being associated with the constant increase in the production of services. In order to explain this phenomenon, Figure
12 reports the significant differences registered from one year to another, for the special case of three categories of higher education graduates (i.e. in technical fields, economics and legal education). The differenced variable of graduates of technical studies, compared to the differenced variables of graduates of economics and legal education, shows important yearly fluctuations, many of these with a positive trend. On the other hand, the fluctuations of the differenced variables of graduates of economics and legal education are generally placed around the initial baseline, without any tendency toward a certain direction, either positive or negative. In plotting the three differenced variables, our intention was to highlight an 


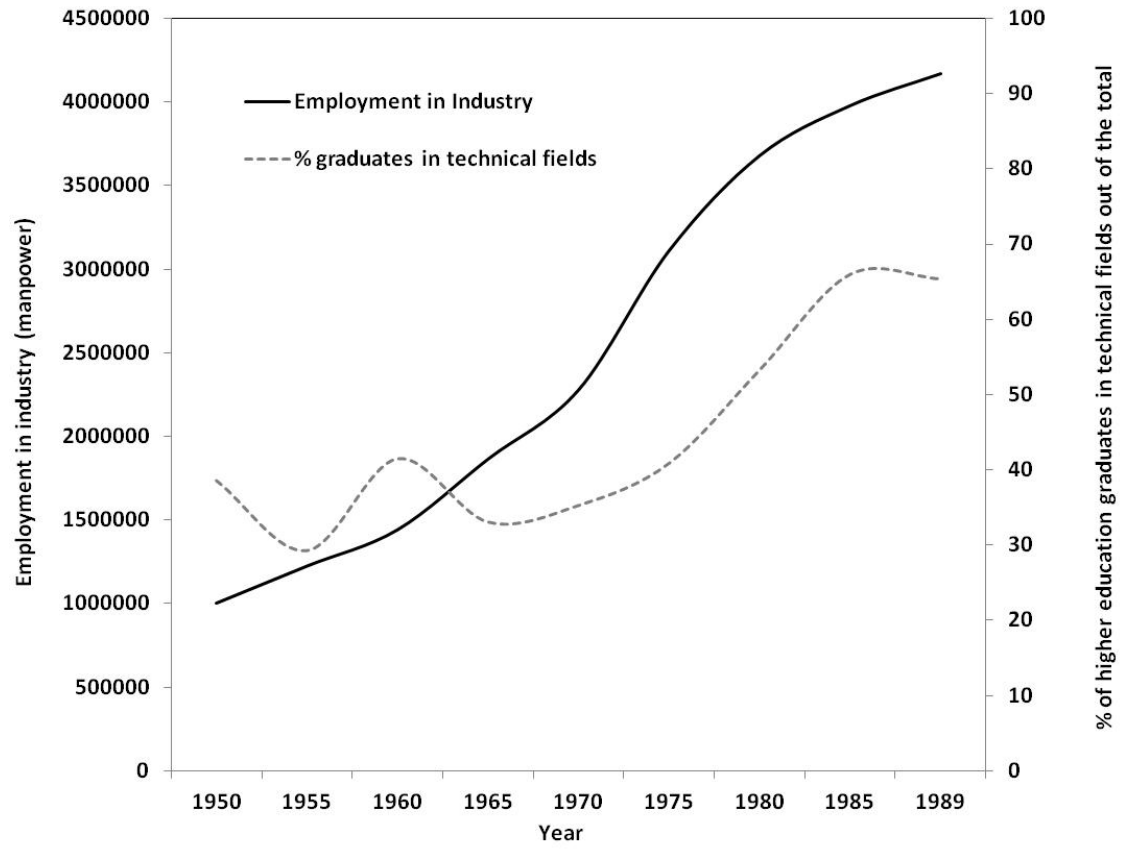

Figure 10. Trends of employment in industry and of higher education graduates in technical fields, for Romania, between 1950 and 1989.

Source of the raw data: Axenciuc, 2012; National Statistics Committee, 1996.

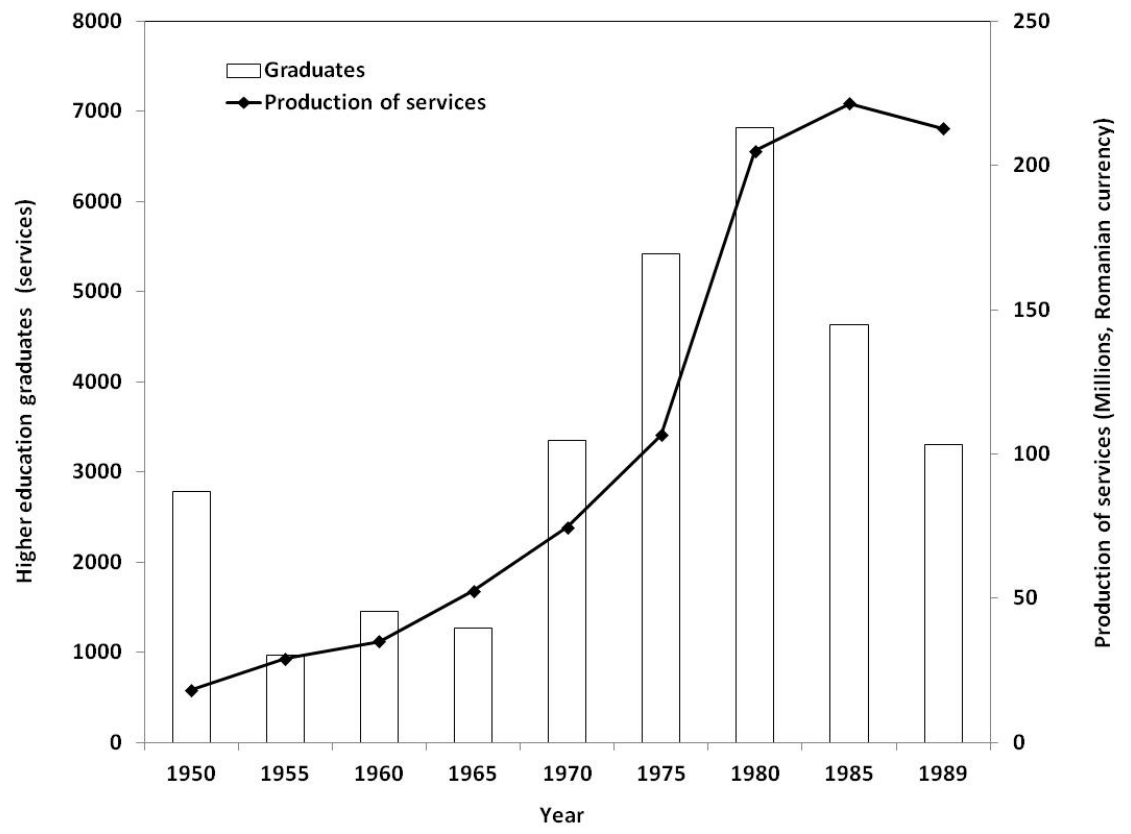

Figure 11. Trends of higher education graduates in the fields of services (e.g. economics, legal education) and the production of services, for Romania, between 1950 and 1989. Source of the raw data: Axenciuc, 2012; National Statistics Committee, 1996 
unexpected or, perhaps, unplanned effect generated during communism: a consistent and substantial growth in the production of services in the context of insignificant oscillations, around the initial baseline, in the numbers of graduates of economics and legal education.

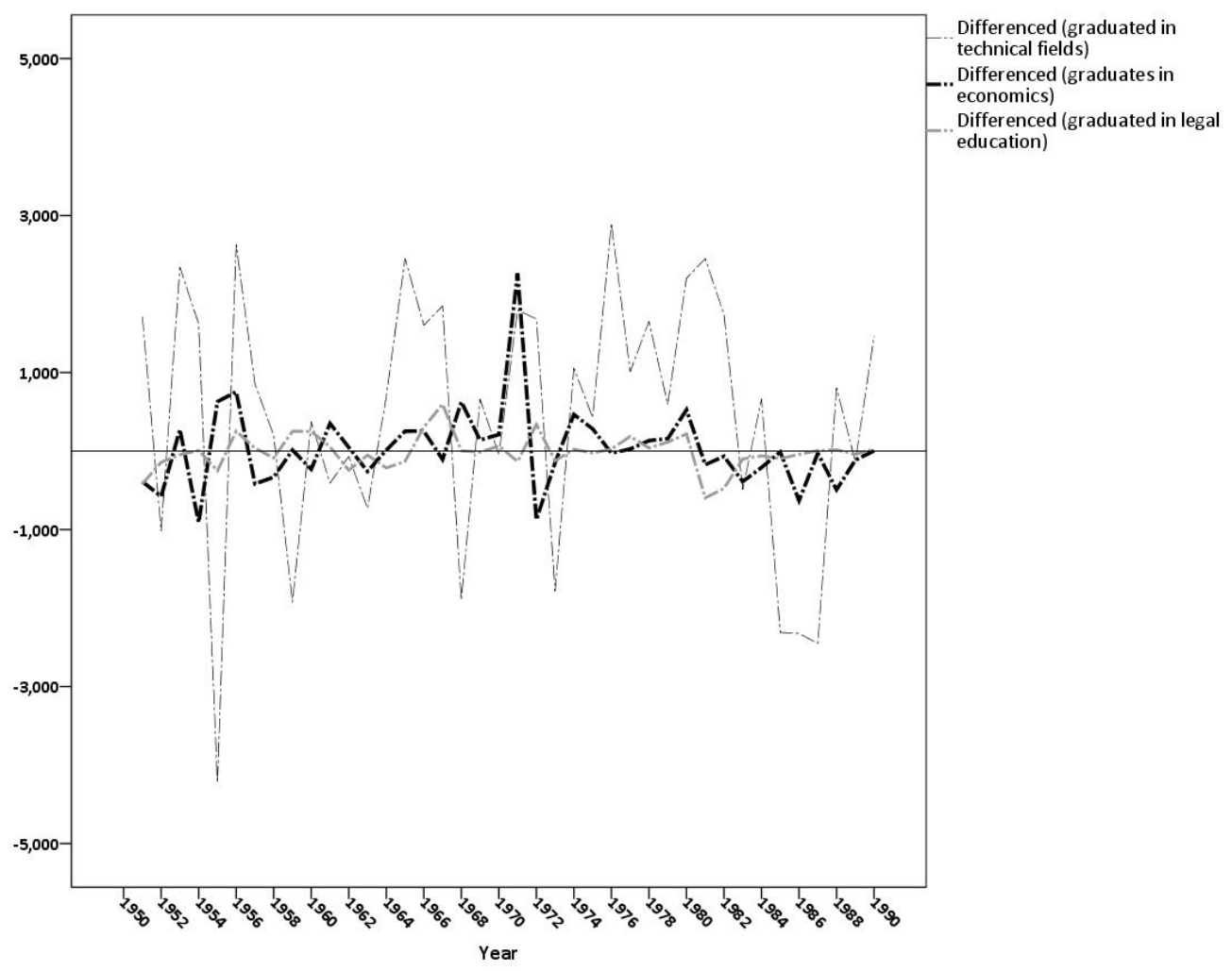

Figure 12. Comparing differenced variables (i.e. resulted after original non-stationary variables were transformed for first order differences, $\left.\Delta y_{t}=y_{t-1} y_{t-1}\right)$ of graduates in technical fields, economics and legal education.

\section{Discussion}

After analyzing time series data on human capital planning during communism in Romania, we discovered that the expected macro-level consequences of normative state planning (such as the increase of technical graduates' flows, of the percentage of educated people or schooling massification, industrialization, urbanization) were associated with unexpected and unintended micro-level consequences (namely, the individual occupational mobility of higher education technical graduates from industrial fields of economy towards areas of services). This phenomenon was supported by a substantial increase in the production of services, given the state's lack of interest in planning large numbers of higher education graduates in educational fields as compared to services, such as economics or legal education.

At first sight, the results we have reported in this paper replicate the findings from other studies: sustained 
industrialization and urbanization (Axenciuc, 2012; Pașca, 2013; Turnock, 1997, 2002), state controlled higher-education system and schooling massification (Mihailescu and Vlasceanu, 1994; Forest and Altbach, 2006; Ruegg, 2011; Sadlak, 1990). However, as opposed to these studies, our approach moves beyond the general macro-level perspective (i.e. general trends in undergraduate and economic flows produced by normative state planning) towards a micro-level perspective (namely, individual occupational migration). We have based our explanations for the unintended effects of normative state planning on the institutional schema for higher education graduates' appointments.

Our study draws on the idea that the inflation of technical higher education graduates triggered by the Romanian communist state to support industry backfired an informal individual occupational mobility towards urban areas that comprised jobs in the sector of services. This unintended consequence of normative planning enforced by the communist regime had at least two causes: (a) the inflation of higher education technical graduates and the shortage of specialists in services, and (b) individuals' desire to explore alternative life projects to the ones created and enforced by the state.

The inflation of engineers was the result of an overextended technical higher education system. More than often, higher education technical graduates (according to estimates, approximately one third out of the total technical graduates) would migrate towards services, which eventually led to the lack of correspondence between their academic training and the professional skills necessary at the work place. Consequently, planning bureaucracy constantly intervened to decrease the percentage of people employed in services. It was a mechanism of permanent correction or adjustment applied to labor force mobility. While planning bureaucrats reduced the number of positions in the service sector, the 'migrant technical graduates' were innovating extraindustrial working opportunities. The formers were enhancing and adjusting the planning of human capital flows. The latter were conceiving entrepreneurial strategies that were tacitly 'cheating' planning control. Similar strategies were undertaken by the technical graduates sent to work in rural areas, and who were permanently seeking opportunities to flee towards urban areas.

The second type of unintended consequences resulted from the planning of compelled appointments in the case of higher education graduates. Graduates were appointed on a meritocratic basis, since appointment considered the average of marks obtained during academic years: the higher the average, the greater the chances to obtain a prestigious position. However, meritocracy was biased by 'informal interventions' eventually producing a twofold effect.

(a) Top graduates were offered a relatively limited array of employment opportunities, while average or below average graduates were offered a relatively higher range of job opportunities (in some cases, even equally prestigious as those provided to top graduates);

(b) Graduates formally placed in the first half of the hierarchy 
hoped in the redistribution of job opportunities within no more than three years after graduation - irrespective of their initial position in the hierarchy, but in close connection with their informal personalized networks.

The competition for excellence in learning did not lead to increased opportunities to obtain a prestigious social position, unless it was completed by certain favorable circumstances. Furthermore, the number of prestigious social positions that eventually decreased in number was dictated by ideological criteria (e.g. the social origin of the graduate, the extent of political involvement and activity, etc.). Receiving a prestigious position was postponed, in some cases, until after the period of compelled appointment was over. Under the given context, escaping the constraints imposed by the planning system was a matter of individual entrepreneurial strategy.

The normative macro-level planning of higher education enhanced the development of individual micro-level strategies of occupational mobility, which diverged from the ethos of the dominant social order.

Although we have identified and stressed the occupational mobility migration of higher education technical graduates from industry towards services as a special type of unintended consequence which backfired on the normative human planning implemented during communism, the idea needs further consideration, refinement and future research. One of the major limitations we were faced with was the lack of substantial quantitative empirical data. Available (time series) statistics on occupational mobility during Romanian communism is rare, if not inexistent. In fact, this is the very case for almost every micro-level social phenomenon of that period (i.e. 1950 1990). Given the circumstances, future qualitative research on the migration of individual higher education technical graduates from industry towards services (including the exchange of imposed rural appointments for urban job opportunities) may provide useful insights into what we call 'individual occupational entrepreneurship'. Furthermore, more qualitative data could better refine the logical implications we derived from the lack of correspondence between the state's macro-level planning of human capital, and individuals' micro-level strategies of maximizing job opportunities after graduating higher education programs.

\section{Conclusions}

The analysis of time series data in education (i.e. education level attainment, higher education graduates divided on specializations), economy (i.e. gross domestic product per capita, production of industrial goods and services) and demography (i.e. rural and urban population) that were collected from multiple sources for the period 1950 - 1990, we have identified findings that, to a consistent degree, replicate former similar studies (education massification, urbanization and industrialization, the increase of industrial productivity etc.). However, the original part of our research consisted in a mixture of macrolevel and micro-level approaches. In this sense, we have looked into 
both the macro-level state planning and potential individual micro-level occupational strategies.

Our main purpose was to inspect the correspondence between normative macro-level planning in higher education (implemented by the communist state) and the de facto microlevel occupational mobility of higher education graduates. We identified a consistent lack of correspondence between higher education graduates' flows and economic production, split on different areas (i.e. industrial, agricultural, services). In this line, the production of services (expressed in Lei - Romanian currency) significantly increased during communism, given an insignificant oscillation in the number of specialists in services and in spite of the state's priority to support industrial production by sustaining large numbers of higher education technical graduates.

During communism, human capital planning failed to enforce and maintain: (i) the correspondence between human capital and undergraduate flows, (ii) the correspondence between the social positions occupied by individuals and their individual profiles in the context of a dominant habitus. The most significant planning failure was determined by individual strategies to maximize personal life chances, after the compulsory appointments that followed higher education graduation. To the vast majority of higher education graduates, their personal life trajectories were the expression of individual social and professional entrepreneurship, rather than the result of the integration and compliance with the official ethos of the communist regime.

Acknowledgements. We would like to thank Professor Bogdan Murgescu and Ph.D. candidate Vlad Pașca for providing us with extremely valuable raw data on graduate flows during the communist regime (i.e. 1950 - 1990).

\section{References}

Axenciuc, V. (2012) Produsul intern brut al României 1862 - 2000. Serii statistice și argumente metodologice. București: Editura Economică.

Barro, R. and J.-W. Lee. 2013. 'Barro-Lee Educational Attainment Dataset'. http:// www.barrolee.com/ (3, March, 2014).

Bolt, J. and J. L. van Zanden (2013). 'The First Update of the Maddison Project;

Re-Estimating Growth Before 1820'. Maddison Project Working Paper 4. Comisia Națională pentru Statistică. 1996. Învățământul în Romania. Date statistice. București: Comisia Națională pentru Statistică. Forest, J. J. F. and P. G. Altbach (2006) (eds.) International Handbook of Higher Education, Part I. Dordrecht: Springer.

Mihăilescu, I. and L. Vlăsceanu (1994) 'Higher Education Structures in Romania'. Higher Education in Europe, XIX(4): 79 - 93.

Pașca, V. (2013) 'Territorial Expansion of Higher Education in Communist Romania (1948 - 1989). An Outline of Patterns and Factors' In Dumitran D. and V. Moga (eds.) Economy and Society in Central and Eastern Europe, pp. 381 - 392. Berlin: LIT VERLAG Dr. W. Hopf. 
Ruegg, W. (2011) (ed.) A History of the University in Europe. Cambridge: Cambridge University Press.

Sadlak, J. (1990) Higher Education in Romania. 1860 - 1990. Between Academic Mission, Economic Demands and Political Control. NY: Buffalo.

Turnock, D. (1997) The Eastern European Economy in Context. Communism and Transition. London: Routledge.

Turnock, D. (2002) The Human Geography of East Central Europe. London: Routledge. 